\title{
CONSTRAINTS ON NORTH AMERICAN-PACIFIC PLATE BOUNDARY DEFORMATION IN CENTRAL CALIFORNIA FROM VLBI AND GROUND-BASED GEODETIC DATA
}

\author{
Jeanne Sauber, Thomas H. Jordan, Gregory C. Beroza \\ Department of Earth, Atmospheric, and Planetary Sciences \\ Massachusetts Institute of Technology \\ Cambridge, MA 02139 \\ Thomas A. Clark \\ NASA-Goddard \\ Greenbelt, MD 20771 \\ Michael Lisowski \\ U.S.G.S. \\ Menlo Park, CA 94025
}

To accommodate the relative motion across the North American-Pacific plate boundary predicted by global plate solutions, significant deformation on faults other than the San Andreas is necessary. In central California, this deformation is thought to include distributed compression perpendicular to the San Andreas as well as right-lateral strike-slip motion parallel to the San Andreas on faults such as the San Gregorio/Hosgri system. A self-consistent set of VLBI observations from experiments beginning in October 1982 is used to determine the vector rate of change of station position at central California VLBI sites Ovro, Mojave, Vandenberg, Fort Ord, Presidio, and Point Reyes. To estimate VLBI station positions, a procedure is used that minimizes the uncertainties in defining a reference frame by including a priori geologic and geodetic information. The vector rate of change of station positions provides constraints on the integrated deformation rates between stations. Geologic and geophysical data suggest that the rate and mode of deformation varies on both local and regional scales. Thus, the VLBI derived results are interpreted in the context of an overall tectonic framework by examining geologic and ground-based geodetic data.

M. J. Reid and J. M. Moran (eds.), The Impact of VLBI on Astrophysics and Geophysics, 353.

(c) 1988 by the IAU. 